\title{
Modified Variance Estimation using New Linear Combination
}

\author{
S. Maqbool and T. A. Raja* \\ Division of AGB, FVSC \& AH, Shuhama, SKUAST-Kashmir, India \\ *Corresponding author
}

A B S T R A C T

\section{Keywords}

Simple random sampling, bias, mean square error, Tri-Mean, Quartile average,auxiliary variable

\section{Article Info}

Accepted:

18 May 2020

Available Online:

10 June 2020
In this paper, we have offered a class of modified ratio type variance estimator for estimation of population variance of the study variable (basic), when Tri Mean and Quartile average of the auxiliary or supplementary variable are known. The bias and mean square error (MSE) of the proposed estimator are obtained. From the numerical study it is observed that the proposed estimator performs healthier under ideal situations than the existing estimators in the literature.

\section{Introduction}

Here we contemplate a finite population $U=\left\{U_{1}, U_{2}, \ldots, U_{N}\right\}_{\text {of }} \mathrm{N}$ distinct and recognisable units. Let $\mathrm{Y}$ be a real variable with value $Y_{i}$ measured on $\mathrm{Ui}, \mathrm{i}=1,2,3, \ldots, \mathrm{N}$ giving a vector $Y=\left\{y_{1}, y_{2}, \ldots, y_{N}\right\}$. The objective is to estimate the population means $\bar{Y}=\frac{1}{N} \sum_{I=1}^{N} y_{I}$ or its variance $S_{Y}^{2}=\frac{1}{N-1} \sum_{I=1}^{N}\left(y_{i}-\bar{y}\right)^{2}$ on the basis of random sample selected from a population U. In sample surveys toghter with the study variable $Y$, data on auxiliary variable $X$, which is positively correlated with $\mathrm{Y}$, is also existing. The data on auxiliary variable $\mathrm{X}$, may be utilized to obtain a more efficient estimator of the population.

During this paper, the aim is to estimate the population variance on the basis of a random sample of size $\mathrm{n}$ nominated from the population $U$.The problem of constructing efficient estimators for the population variance has been widely deliberated by various authors likeIsaki (1983), who proposed ratio and regression estimators. 
Prasad and Singh (1990) considered a ratio type estimator for estimating population variance by refiningIsaki's(1983) estimator. Latter varied authors such as Kadilar\&Cingi (2006), Subramani\&Kumarapandiyan (2015) improved the already existing estimators by introducing reformed estimators with the use of known parameters like C.V, Kurtosis, Median, Quartiles and Deciles.

\section{Notations}

$\bar{X}, \bar{Y}=$ Population means. ${ }^{\bar{x}}, \bar{y}=$ Sample means. $S_{Y}^{2}, S_{x}^{2}=$ population

variances. $s_{y}^{2}, s_{x}^{2}=$

sample

variances. $C_{x}, C_{y}=$ Coefficient of variation., $\rho=$ Correlation

coefficient. $\beta_{1(x)}=$ Skewness of the auxiliary variable. $\beta_{2(x)}=$ Kurtosis of the auxiliary variable. $\beta_{2(y)}=$ Kurtosis of the study variable., $\mathrm{M}_{\mathrm{d}}=$ Median of the auxiliary variable. $\mathrm{B}()=$. Bias of the estimator., $\operatorname{MSE}()=$. Mean square error. $\hat{S}_{R}^{2}=$ Ratio type variance estimator., $\hat{S}_{K c 1}^{2}, \hat{S}_{j G}^{2},=$ Existing modified ratio estimators. $\mathrm{Q}_{\mathrm{a}}=\left(\mathrm{Q}_{3}+\mathrm{Q}_{1} / 2\right.$, Population semi-quartile average of the auxiliary variable x. $T M=\left(Q_{1}+2 Q_{2}+Q_{3}\right) / 4$, Tri-Mean.

Ratio type variance estimator proposed by Isaki (1983)

Isaki steered a ratio type variance estimator for the population variance $S_{Y}^{2}$ when the population variance $S_{x}^{2}$ of the auxiliary variable $\mathrm{X}$ is known. Its bias and mean square error are

$$
\hat{S}_{R}^{2}=s_{y}^{2} \frac{S_{x}^{2}}{s_{x}^{2}}
$$

$\operatorname{Bias}\left(\left(\hat{S}_{R}^{2}\right)=\gamma S_{y}^{2}\left[\left(\beta_{2(x)}-1\right)-\left(\lambda_{22}-1\right)\right]\right.$

$\operatorname{MSE}\left(\left(\hat{S}_{R}^{2}\right)=\right.$ $\gamma S_{y}^{4}\left[\left(\beta_{2(y)}-1\right)+\left(\beta_{2(x)}-1\right)-2\left(\lambda_{22}-1\right)\right]$

\section{Kadilar and Cingi (2006) estimators}

The authors advocated four ratio type variance estimators using known values of C.V and coefficient of kurtosis of an auxiliary variable $X$.

$$
\hat{S}_{k c 1}^{2}=s_{y}^{2}\left[\frac{S_{x}^{2}+C_{x}}{s_{x}^{2}+C_{x}}\right]
$$

$\operatorname{Bias}\left({ }^{\left(S_{k c 1}^{2}\right)}=\right.$

$\gamma S_{y}^{2} A_{1}\left[A_{1}\left(\beta_{2(x)}-1\right)-\left(\lambda_{22}-1\right)\right]$

$\operatorname{MSE}\left({ }^{\left(\hat{S}_{k c 1}^{2}\right)}=\right.$

$\gamma S_{y}^{4}\left[\left(\beta_{2(y)}-1\right)+A_{1}^{2}\left(\beta_{2(x)}-1\right)-2 A_{1}\left(\lambda_{22}-1\right)\right]$

$\hat{S}_{k c 2}^{2}=s_{y}^{2}\left[\frac{S_{x}^{2}+\beta_{2(x)}}{s_{x}^{2}+\beta_{2(x)}}\right]$

$\operatorname{Bias}\left({ }^{\left(\hat{S}_{k c 2}^{2}\right)}=\right.$

$\gamma S_{y}^{2} A_{2}\left[A_{2}\left(\beta_{2(x)}-1\right)-\left(\lambda_{22}-1\right)\right]$

$\operatorname{MSE}\left(\stackrel{\left(\hat{S}_{k c 2}^{2}\right)}{ }\right)$
$\gamma S_{y}^{4}\left[\left(\beta_{2(y)}-1\right)+A_{2}^{2}\left(\beta_{2(x)}-1\right)-2 A_{2}\left(\lambda_{22}-1\right)\right]$

$\hat{S}_{k c 3}^{2}=s_{y}^{2}\left[\frac{S_{x}^{2} \beta_{2(x)}+C_{x}}{s_{x}^{2} \beta_{2(x)}+C_{x}}\right]$

$\operatorname{Bias}\left({ }^{\left(\hat{S}_{k c 3}^{2}\right)}=\right.$

$\gamma S_{y}^{2} A_{3}\left[A_{3}\left(\beta_{2(x)}-1\right)-\left(\lambda_{22}-1\right)\right]$ 
$\operatorname{MSE}\left(\stackrel{\left(\hat{S}_{k c 3}^{2}\right)}{ }=\right.$
$\gamma S_{y}^{4}\left[\left(\beta_{2(y)}-1\right)+A_{3}^{2}\left(\beta_{2(x)}-1\right)-2 A_{3}\left(\lambda_{22}-1\right)\right]$

$\hat{S}_{k c 4}^{2}=s_{y}^{2}\left[\frac{S_{x}^{2} C_{x}+\beta_{2(x)}}{s_{x}^{2} C_{x}+\beta_{2(x)}}\right]$

$\operatorname{Bias}\left(\hat{S}_{k c 4}^{2}\right)=$

$\gamma S_{y}^{2} A_{4}\left[A_{4}\left(\beta_{2(x)}-1\right)-\left(\lambda_{22}-1\right)\right]$

$\operatorname{MSE}\left({ }^{\left(\hat{S}_{k c 4}^{2}\right)}=\right.$

$\gamma S_{y}^{4}\left[\left(\beta_{2(y)}-1\right)+A_{4}^{2}\left(\beta_{2(x)}-1\right)-2 A_{4}\left(\lambda_{22}-1\right)\right]$

\section{Recent advances}

Subramani and Kumarapandiyan (2015) developed estimators by utilizing median, quartiles and Deciles of an auxiliary variable.

$\hat{S}_{j G}^{2}=s_{y}^{2}\left[\frac{S_{x}^{2}+\alpha w_{i}}{s_{x}^{2}+\alpha w_{i}}\right]$

$\operatorname{Bias}\left({ }^{\left(\hat{S}_{j G}^{2}\right)}=\right.$ $\gamma S_{y}^{2} A_{j G}\left[A_{j G}\left(\beta_{2(x)}-1\right)-\left(\lambda_{22}-1\right)\right]$

$\operatorname{MSE}\left({ }^{\left(\hat{S}_{j G}^{2}\right.}\right)=$

$\gamma S_{y}^{4}\left[\left(\beta_{2(y)}-1\right)+A_{j G}^{2}\left(\beta_{2(x)}-1\right)-2 A_{j G}\left(\lambda_{22}-1\right)\right.$

When $\alpha=0$ in equation (6), the above estimator reduces to Isaki (1983) estimator.

When $\alpha=1$ in equation (6), the above estimator reduces to Kadilar and Cingi (2006) estimator.

\section{Proposed estimator}

Flowing the trend we proposed a new modified ratio type variance estimator of the auxiliary variable by using linear combination of Tri-mean and population semi inter quartile average of the auxiliary variable. It is highly sensitive to outliers as its design structure is based on only extreme values of the data ( for more details see Ferrell (1953)).

$$
\hat{S}_{M S}^{2}=s_{y}^{2}\left[\frac{S_{x}^{2}+\left(T M+Q_{a}\right)}{S_{x}^{2}+\left(T M+Q_{a}\right.}\right]
$$

The bias and mean square error of the above estimator after simplification is

$\operatorname{Bias}\left(\hat{S}_{M S}^{2}\right)=$
$\gamma S_{y}^{2} A_{S R}\left[A_{S R}\left(\beta_{2(x)}-1\right)-\left(\lambda_{22}-1\right)\right]$

$\operatorname{MSE}\left({ }^{\left(\hat{S}_{M S}^{2}\right)}=\right.$

$\gamma S_{y}^{4}\left[\left(\beta_{2(y)}-1\right)+A_{S R}^{2}\left(\beta_{2(x)}-1\right)-2 A_{S R}\left(\lambda_{22}-1\right)\right]$

Where $\mathrm{A}_{\mathrm{MS}}=\frac{S_{X}^{2}}{S_{X}^{2}+\left(T M+Q_{a}\right)}$

\section{Numerical illustration}

We use the data of Murthy (1967) page 228 in which fixed capital is denoted by $\mathrm{X}($ auxiliary variable ) and output of 80 factories are denoted by Y(study variable).we apply the proposed and existing estimators to this data set and the data statistics is given below:

$\mathrm{N}=80, \mathrm{Sx}=8.4542, \quad \mathrm{~A} 2=0.9615, \quad \mathrm{n}=20$, $\mathrm{Cx}=0.7507, \quad \mathrm{~A} 3=0.9964$, $\bar{X}=11.2624,{ }_{2(x)}=2.8664 \mathrm{~A} 4=0.9493$, $\bar{Y}=51.8264, \quad \beta_{2(y)}=2.2667, \quad \mathrm{AjG}=0.8763$, $\rho={ }_{0.9413,}{ }_{1(x)}={ }_{1.05} \quad \lambda_{22}=2.2209$, $\mathrm{S}_{\mathrm{y}}=18.3569, \quad \mathrm{Md}=7.5750, \quad \mathrm{Q} 1=9.318$, $\mathrm{C}_{\mathrm{y}}=0.3542, \quad \mathrm{~A} 1=0.9896$, $\mathrm{Q} 2=7.5750, \mathrm{Q} 3=16.975, \mathrm{QD}=5.9125$, $\mathrm{Qa}=11.0625, \quad \mathrm{QR}=11.82, \quad \mathrm{TM}=9.318$, $\mathrm{TM}=9.318$ 
Table.1 Bias and Mean Square Error of the existing and the proposed estimators

\begin{tabular}{|l|l|l|}
\hline Estimators & Bias & $\begin{array}{l}\text { Mean Square } \\
\text { Error }\end{array}$ \\
\hline Isaki (1983) & 10.8762 & 3925.1622 \\
\hline Kadilar \& Cingi(2006) 1 & 10.4399 & 3850.1552 \\
\hline Kadilar \&Cingi(2006) 2 & 9.2918 & 3658.4051 \\
\hline Kadilar \& Cingi(2006) 3 & 10.7222 & 3898.5560 \\
\hline Kadilar \& Cingi(2006) 4 & 8.8117 & 3580.8342 \\
\hline Subramani \& Kumarapandiyan(2015) & 6.1235 & 3180.7740 \\
\hline Proposed Estimator ( MS) & $\mathbf{3 . 0 2 8 9}$ & $\mathbf{2 8 2 0 . 0 6}$ \\
\hline
\end{tabular}

The paper proposes a ratio type variance estimator using known values of an auxiliary variable. Results show that the bias and mean square error are less than the already existing estimators in the literature and the percentage relative efficiency comes out be $139.18 \%$. Hence the proposed estimator may be favoured over existing estimators in ideal situations for use in practical.

\section{References}

Cochran , W. G. (194). Sampling Techniques. Third Edition, Wiley Eastern limted.

Ferrell, E. B. (1953). Control charts using Mid ranges and Medians. Industrial Quality control,9(5), 30-34.

Isaki, C.T. (1983). Variance estimation using auxiliary information. Journal of the American Statistical Association, 78, 117-123.
Kadilar, C. \&Cingi, H. (2006). Improvement in Variance estimation using auxiliary information. Hacettepe Journal of mathematics and Statistics, 35(1).117115.

Murthy, M. N. (1967). Sampling theory and methods. Calcutta Statistical Publishing House, India.

Prasad, B., and Singh, H. P. (1990).Some improved ratio type estimators of finite population variance in sample surveys. Communication in Statistics: Theory and methods, 19, 1127-1139.

Sumramani, J. and Kumarapandiyan, G. (2015).Generalized modified ratio type estimator for estimation of population variance. Sri-Lankan journal of applied Statistics,voll61,69-90.

Wolter, K. M. (1985). Introduction to variance estimation. Springer-Verlag.

\section{How to cite this article:}

Maqbool. S. and Raja. T. A. 2020. Modified Variance Estimation using New Linear Combination. Int.J.Curr.Microbiol.App.Sci. 9(06): 957-960.

doi: https://doi.org/10.20546/ijcmas.2020.906.120 